\title{
Research on Engineering Cost Control from the Perspective of Enterprise Project Management
}

\author{
Li Jin \\ Chengdu Normal University, Chengdu, Sichuan, 610031, China
}

Keywords: Enterprise project management, Engineering cost control, Requirements, Ideas, Control methods.

\begin{abstract}
The perspective of enterprise project management is an innovative perspective from the engineering cost control of current enterprises, which is profound and clear for the research on the theory and practice of enterprise project management and can be considered according to the characteristics of enterprise management theory. The ideas and methods for the engineering cost control from the perspective of enterprise project management are put forward in this paper.
\end{abstract}

\section{Introduction}

As early as in 1970s, two international project management organizations, the International Project Management Association (IPMA) and the Project Management Institute, began to promote the development of the project management subject energetically. Eventually, a general project management system in broad sense was formed in 1990s, which also became an important theory of the enterprise project management. For the enterprises, how to complete the engineering cost control well with this system to obtain more economic and social benefits is crucial.

\section{Theories related to enterprise project management}

The enterprise project management involves the theories in many aspects, but here we mainly analyze its basic theoretical connotation, characteristics and management requirements.

\subsection{Basic theoretical connotation of enterprise project management}

IPMA put forward the concept of the enterprise project management in 1999 and defined it as the core management content of long-term organizations. Besides, it defined the project management deeply and clarified its basic objectives of project strategy.

In 2000, the Association for Project Management (APM) put forward a new management concept of the integration of project set management with the organization, in which the enterprise project management content includes the value management, strategic management, their respective characteristics and combined achievements. After that, it became an important method for the organizational strategic planning. Specifically speaking, the enterprise project management standard includes five levels: main project, subproject, project set, project portfolio and strategic plan. By reasonable grading, the policy matching the project office and strategy is put forward to highlight the higher-level connotation of the enterprise project management.

In accordance with the past international research results, a project cluster management method has been proposed for the enterprise project management, which is very suitable for the engineering cost control of enterprises. Because its management range is wide and it is a process project management method to reflect and explain the whole management process of project-based business activities very well, it has become an important basis for enterprises to build the strategic project management system. 


\subsection{Basic theoretical characteristics of enterprise project management}

For enterprises, project management refers to participating in the whole management process of the project content by some way, which involves all internal and external contents of an enterprise project. Its purposes are to meet the various services and project needs of the enterprise itself and ensure the comprehensive implementation of the engineering cost control process of the enterprise. The enterprise project management has the following 4 basic theoretical characteristics.

First of all, it is related to the construction of the strategic management system of the enterprise project. The construction industry is the first to apply the theory of project management. Many project management contents will be involved in the processes of various projects, which are a big test for the long-term organizational work of the enterprises. Therefore, the enterprises shall consider how to match the projects with their own objectives, so as to manage the projects better and deeply, abandon the traditional temporary management practices, and ensure the long-term and sustainable development of enterprises in project management and comprehensive management.

Secondly, it provides a life-cycle project management concept for the enterprises. It solves the temporary organizational contradictions in the business operation, and meets the requirements of the operations management after the project is over at the same time. The project management can be divided into 3 important stages: decision-making before construction, construction process advancement and operation after construction.

Thirdly, it provides the enterprises with the concept of multi-project management and related methods. Each project in an enterprise develops to varying degrees, so there may be many differences in the development of the different project contents at the same time, which will affect the orderly management of projects in the different life-cycle stages. In other words, the enterprise project management shall take into account the effective implementation of technical management application methods for single project and multiple projects at the same time, and put forward new management methods for the project set and project portfolio, in order to realize the multi-project synchronous management truly.

Fourthly, it realizes the whole-process resource management for the enterprises. By minimizing the consumption of resources in the operating process, it can make the most operating profits for the enterprises and provide effective resources for the enterprises to the greatest extent to ensure the sustainable development of the enterprises. Actually, the shortage of resources in the domestic enterprises is still very serious at present, so they consider adding the concept and practice of the enterprise project resource management, in order to create favorable conditions for the enterprises to rationally utilize the resources, optimize the allocation of resources, and occupy a favorable position in the competitive market.

\subsection{Basic requirements of enterprise project management}

Enterprise project management refers to managing the projects in which the enterprise participates with specific modes and tools in a specific environment, so as to meet all the project contents and customer demands. Generally speaking, the basic requirements of the enterprise project management shall include the following two points.

Firstly, the requirements of the enterprise project management are related to enterprise strategy. Various engineering projects will be undertaken in the construction industry. In order to promote the construction progress of the project effectively, it is necessary to dynamically adjust the management method of the enterprise and ensure the enterprise project management is matched with the enterprise's overall strategy all the time to support the development and growth of the management organization and lay a foundation for the sustainable development of the enterprise in the future.

Secondly, the requirements of the enterprise project management run through the whole life cycle of the project. The enterprise project management has two characteristics, temporality and long term and the two characteristics are contradictory, so enterprises must put the project management throughout the whole life cycle of project construction and adjust each link of the project actively according to the specific management content and related measures to ensure the orderliness of 
project management .

\section{Basic ideas for engineering cost control from the perspective of enterprise project management}

From the perspective of enterprise project management, in this paper, the author thinks that the engineering cost control must be completed well in the whole process of the construction project and the effectiveness of project management shall be highlighted to save a large number of costs for the enterprises. For this purpose, 3 basic ideas for the engineering cost control from the perspective of enterprise project management are put forward in this paper.

\subsection{Effective planning for bidding and tendering of project}

The planning for the bidding and tendering of a project is the initial work and foundation for the engineering project construction of an enterprise. The theories related to the enterprise project management shall be followed in the operational process and the following three points shall be completed in the bidding process to ensure that the engineering cost control is advantageous.

First of all, compile and manage the tendering documents well. Before tendering, it is necessary to analyze the project overview, put forward relevant requirements for the design quality of the project, and delimit the tendering scope and the valuation content and method clearly.

Secondly, standardize the management of bidding and tendering to ensure the orderliness of the bidding and tendering of the engineering project, strive to effectively and strictly review the qualifications of the organizations in the form of procedures before tendering, release the tendering announcement and related documents, and submit them to the evaluation team to discuss and decide the final winner.

Thirdly, manage the contract well to ensure that the contract plays the role of binding force in the whole construction period and can control the engineering cost to a certain extent. For the implementation of enterprise project management, the key point is to estimate the valuation method for the engineering cost and the materials, but the most important thing is to complete the project settlement well to realize the good enterprise project management from the beginning to the end.

\subsection{Effective control of engineering cost in construction stage}

During the construction period, be sure to control the engineering cost effectively and follow the enterprise project management theory mentioned above to manage the related content of the engineering construction orderly. Specifically, complete the following two points well:

Control the consumption and prices of the engineering materials, and regard the material as an important part of the engineering project. The engineering materials shall account for about $70 \%$ of the total cost budget of the project, so it is necessary to control their actual consumption and prices strictly. We can choose the suppliers according to the economic conditions of enterprise and the actual situation of the market, and confirm the material types and price differences, to make a reasonable choice at last, thus being conducive to the effective engineering cost control.

Master the related content of the engineering cost management and define the final control content in the completion stage in order to provide important references for the enterprise project management. Specifically speaking, the engineering cost control in the completion stage shall be carried out focusing on the theory of enterprise project management. First of all, ensure that the settlement materials are complete, because the complete materials can prove the completion of the rationality and authenticity of the settlement of the final account. Therefore, it is necessary to completely eradicate some temporary effort phenomenon, such as to provide the materials while auditing, in the review process, because this behavior is not compliant and shall be stopped to avoid its impact on the final account.

Secondly, check the related quantities. Provide the design change plan with the construction drawings according to the current relevant provisions, so as to further specify the audit content of the quantities of whole project. 
Thirdly, apply the quota accurately and realize the cross rate of quota in the application process of quota, but in the actual operation process, if there is a quota deficiency, the engineering cost control shall be relocated in accordance with related data and actual situation to make up for the quota deficiency, and then clarify the unit prices of project construction.

Finally, audit the material prices accurately. In this process, it is necessary to make clear which materials need to be priced differentially and avoid the illegal price adjustment. In addition, verify the Consumption of materials accurately according to the design drawings and the materials related to the quota audit. Moreover, it is necessary to compare the settlement price with the market price in the construction process. If an audit difference is found, it shall be reported to the superior, and consider whether to apply the current material prices to re-quote in order to meet the conditions for the engineering cost control.

\section{Control methods for engineering cost control from the perspective of enterprise project management}

From the perspective of enterprise project management, there are many engineering cost control methods, which mainly focus on 3 points: the cost forecast in the bidding and tendering stage, the cost control in the construction stage, and the compilation and audit after the completion. Next, the engineering cost control methods are introduced focusing on the 3 points from the perspective of the enterprise project management.

\subsection{Whole flow of engineering cost control methods}

First of all, specify the whole flow of engineering cost control methods, which is shown as follows:

Project tendering — tender offer — daily change and claim for compensation inconstruction completion settlement — settlement audit analysis.

\subsection{Analysis of cost forecast and cost control in bidding and tendering stage}

The overall engineering cost shall be forecasted and controlled in the bidding and tendering stage. Specifically speaking, combined with accurate evaluation, the construction period, quality, required techniques and capital consumption of the project, and the contract mode and settlement method after the bid is won shall be analyzed deeply combined with the accurate assessment. The audit shall be carried out according to the design drawings to ensure the accurate forecasted cost. Concretely, the following cost forecast control methods can be provided.

The unbalanced bidding method is a common cost control method in the construction of enterprise engineering projects at present, by which all the contents of the project in the bidding and tendering stage can be examined from the perspective of enterprise project management. Determine the total cost based on not affecting the tender sum, put forward the double objectives to obtain more economic benefits in the settlement process, and adjust and plan the unit prices of individual items within the enterprise effectively.

Another method is the method of small profits entering the market, which is very suitable for the stage construction based on the cost control of auxiliary works by installments. For example, apportion a part of indirect costs in the phase-I tendering process. Try to win the bidding as early as possible in the project, and make full use of the reputation and construction experience in the phase-I project to win the phase-II project successfully, to achieve small profits but quick turnover.

In addition to the above two methods, there are some other methods for the engineering cost control from the perspective of enterprise project management, such as the multi-scheme offering method, sudden price reduction method and preference commitment method, all of which have corresponding conditions and relevant appeals in the bidding and tendering schemes to catch other people's attention. 


\subsection{Cost control method in construction stage}

The cost control in the construction stage is the most crucial. First of all, control the purchase prices and quantity of materials, and then achieve the cost management in accordance with the engineering changes, put forward the scheme to change the design, and expand the scale of bidding project effectively, to ensure the maximum project benefits.

In addition, the enterprise engineering cost control must play an organizational role in strengthening the technology, controlling the investment and ensuring the mutual improvement of technology and economy. Therefore, the economic concept and vocational and technical qualities of technicians and constructors must be strengthened in the construction management, so as to improve project quality effectively.

\subsection{Settlement preparation and audit method in completion stage}

In the completion stage, collect and sort out a large number of completion data to provide relevant data for the final integration of the engineering, integrate the previous completion design drawings, design change schemes and various certifications one by one, and analyze and settle the project funds, so as to output costs for the final engineering cost control ${ }^{[3]}$.

\section{Summary}

To sum up, for the engineering cost control from the perspective of enterprise project, the content of each stage of the project shall be designed elaborately, and the cost accounting and cost control process shall be perfected scientifically, and the construction progress of enterprise projects shall be accelerated, in order to cater to the important theory of enterprise project management praised by the state highly for the future development and lay a solid foundation for the enterprise to occupy a space in the competitive market economy.

\section{References}

[1] Jia Shaokun, Engineering Cost Control from Perspective of Enterprise Project Management, China Journal of Commerce, 2016 (9): 46-48.

[2] Wei Baoping, Whole-process Management and Control of Engineering Cost for Construction Enterprises, Modern Business, 2013 (3): 81-82.

[3] Zhao Hong, Li Xuliang, the Research on Engineering Cost Control under the Perspective of Enterprise Project Management, Value Engineering, 2017 (13): 21-22. 